This is a postprint version of the following published document:

Pernas-Sánchez, J., Artero-Guerrero, J.A., Varas, D., \& López-Puente, J. (2016). Experimental analysis of ice sphere impacts on unidirectional carbon/epoxy laminates. International Journal of Impact Engineering, 96, pp. 1-10.

DOI: $\underline{10.1016 / \text { j.ijimpeng.2016.05.010 }}$

(C) Elsevier 2016

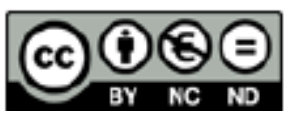

This work is licensed under a Creative Commons Attribution-NonCommercialNoDerivatives 4.0 International License. 


\title{
Experimental analysis of ice sphere impacts on unidirectional carbon/epoxy laminates
}

\author{
J. Pernas-Sánchez, J.A. Artero-Guerrero, D. Varas, J. López-Puente* \\ Department of Continuum Mechanics and Structural Analysis. University Carlos III of \\ Madrid. Avda. de la Universidad, 30. 28911 Leganés, Madrid, Spain
}

\begin{abstract}
This work analyses the behaviour of carbon/epoxy unidirectional laminates subjected to high velocity impacts of ice spheres. To this end, ice projectiles were launched against composite laminates in a wide range of velocities (50 $250 \mathrm{~m} / \mathrm{s}$ ). Two different ice diameters $(40$ and $50 \mathrm{~mm}$ ) and two laminate thicknesses (4 and $6 \mathrm{~mm}$ ) were considered. The internal damage was measured using both destructive and non-destructive techniques, which allow an accurate quantification of the delaminated area. Finally the influence of the different parameters considered on the damage of the laminate is analysed by means of a dimensionless variable.

Keywords: Ice behaviour; composite laminate; impact; experimental; failure mechanism.
\end{abstract}

\section{Introduction}

Composite materials are increasingly used to manufacture aircraft and aeronautic structures due to their excellent mechanical properties and their low density. In particular carbon/epoxy laminates (CFRP) represent probably the best combination of matrix and reinforcement in terms of strength to weight ratio. During flight, landing and take off, aeronautic structures could be subjected to several types of loads, both static and dynamic and in particular impacts. It is important to highlight that laminates are quite sensitive to impact loads, in particular when they are applied perpendicularly to the plane. The first attempts to understand the behaviour of composite laminates under high velocity impact were done around 1970, mainly by the military administrations; for example it is possible to find NATO documents regarding this subject. In the 1980 s and in the 1990 s some articles were published regarding the high velocity impact on composite laminates, mainly from an experimental perspective [1-5]. Those works were the first that analysed the different failure mechanisms that appear under impact conditions.

From the 2000 several works have been published about the effect of low and high impact velocities of metallic fragments on carbon/ epoxy laminates from both experimental and numerical perspective. An analysis from the experimental point of view of the behaviour

\footnotetext{
* Corresponding author. Department of Continuum Mechanics and Structural Analysis, University Carlos III of Madrid, Avda. de la Universidad, 30, 28911 Leganés, Madrid, Spain. Tel.: +34916248881; Fax: +34916248881.

E-mail address: jlpuente@ing.uc3m.es (J. López-Puente).
}

of carbon/epoxy laminate under impact of small hard fragments can be found in several works [6-17]. In addition, due to the intense use of computational tools to model the behaviour of structures under different kind of loads, several articles have focused their attention in the development of constitutive models for these materials [17-19].

Many efforts have been done to study the response of laminate structures subjected to the impact of hard bodies, nevertheless it is worth to mention that the debris which impact a composite structure could be hard or soft bodies. In the first group are included metallic pieces left in the runaway, or fragments from an uncontained engine failure; the second group is related mainly to bird strike or ice impacts. Ice impact could come from hailstone, and also could be formed in convex structures (such as blade propellers or leading edges) that could be released when they reach a critical mass. Therefore it is necessary to understand how that kind of impacts affect the composite structures.

The behaviour of composite laminates under high velocity impacts of soft bodies has received less attention because of its higher complexity: in those problems both the impactor and the target get deformed (rigid body assumption for the debris is no longer possible). Johnson and Holzapfel [20] in 2003 published an article in which gelatine (to study the bird impact) was launched at high velocity against a curved woven composite structure; they show that the laminate failure was mainly due to fibre cracking and delamination, but without providing an analysis of the effect of the impact energy on the damage induced. A very similar approach was performed by McCarthy et al. [21] in 2004, launching gelatine against a real leading edge including ribs. Hou and Ruiz [22] in 2007 performed high velocity impact tests of gelatine on different 
composite plates (at different impact velocities) with an extensive analysis of the damage mechanism.

Another soft impactor which is important for the aeronautic industry is the ice. To study the effect of high velocity impacts on composite laminates, it is necessary to understand how the ice behaves at high strain rates. The mechanical behaviour of the ice has been widely investigated from the fields related to geology, mainly from the oil and gas industries; nevertheless the behaviour of the ice under impact conditions has received less attention. The first works related to the mechanical properties of the ice are dated in the 1980s and the 1990s [23-26]. The main conclusions of those works were that the microstructure and the temperature affect considerably the properties of the ice under quasi-static conditions; in addition a transition from ductile to brittle behaviour was found at low strain rates (below $10^{-2} \mathrm{~s}^{-1}$ ). This is a very important conclusion, since it means that in applications such as the one studied in the present work (high velocity impacts), it is necessary to consider the ice as a brittle material. Regarding the behaviour of ice under high strain rates, different authors [27-33] have studied both experimentally and numerically the high velocity impact of ice against rigid panels. One of the main conclusions extracted was that the micro-structure does not play an important role under these conditions, and that a correlation exists between the impact force and the kinetic energy.

The number of works that have studied the effect of a high velocity impact of ice on composite laminates are scarce. The first studies found dated on the 2000, when Kim et al. [31,34] analysed the effect of the high velocity impact of ice spheres of different diameters (up to $50 \mathrm{~mm}$ ) on woven carbon/epoxy panels. They were the first in identifying the damage failure mechanisms that appear in this kind of impacts; they also considered different ice structures, finding no dependence. Finally, for each combination of ice mass and laminate thickness, the minimum kinetic energy (failure threshold energy) that produces any type of damage was obtained. More recently in 2009 Asp and Juntikka [35] performed experimental tests of ice spheres (up to $50 \mathrm{~mm}$ ) on non-crimp fabric composites analysing, by means of micrographs, the damage mechanisms that appear in that type of laminates. In the same year Hong et al. [36] performed experimental tests of ice particles (around $3 \mathrm{~mm}$ in diameter) at very high velocity (up to $900 \mathrm{~m} / \mathrm{s}$ ) on fabric laminates; the authors analysed the damage pattern and also the debris produced due to the high velocity impact. Juntikka and Olsson [37] also performed experimental tests on carbon/vinylester noncrimp fabrics, obtaining the impact velocity necessary to promote delamination; in addition an analytical model to predict this velocity was proposed. In 2011, Appleby-Thomas et al. [33] studied the effect of multiple impacts of small ice projectiles ( $22 \mathrm{~mm}$ of diameter) on carbon/epoxy woven and non-crimp fabric; an analysis of the damage extension and the residual strength is performed. Finally in 2012 Rhymer et al. [38] performed impacts of ice spheres on hybrid panels composed by glass/epoxy and carbon/epoxy plies. They calculated the damaged area with different non-destructive techniques, and evaluated the failure threshold energies and velocities.

It is worth to mention that it was not possible to find any work which studies the high velocity impact of ice on thick (up to $6 \mathrm{~mm}$ ) and large $(300 \times 300)$ composite tape laminates, being this architecture the most common in the civil aircraft industry. The aforementioned works which study the ice impact on woven or tape laminates always consider small thickness (up to $4 \mathrm{~mm}$ ) in large panels (close to $300 \times 300 \mathrm{~mm}^{2}$ ) or larger thickness (up to $6 \mathrm{~mm}$ ) in small panels $100 \times 150 \mathrm{~mm}^{2}$; it is important to highlight that the characteristic length of composite panels in aircraft structures (distance between stringers) is approximately $300 \mathrm{~mm}$.

The objective of this work is to analyse the influence of the high velocity impacts of ice spheres on a carbon/epoxy tape composite laminate. Two different ice diameters (40 and $50 \mathrm{~mm}$ ) and two laminate thicknesses ( 4 and $6 \mathrm{~mm}$ ) are studied. In order to study the influence of the impact, the non-destructive techniques C-scan and phase-array are used to precisely quantify the internal damaged area; in addition, a laser extensometer was used to measure the displacement of the centre of the plate during the impact. A further analysis of the influence of each of the parameters studied is carried out. The following section presents the experimental methodology used in the impact test, describing the methodology to obtain the ice projectiles, the CFRP coupons used and the experimental devices. In Section 3, the results of these impact tests are given. Subsequently a discussion of the results based in a dimensionless parameter is proposed. Finally, the conclusions of the work are presented.

\section{Description of the experiments}

Experimental tests of high velocity impacts of ice spheres against carbon/epoxy tape laminates were performed at the Impact Laboratory of the University Carlos III of Madrid. In this section, the materials and the experimental devices used in the tests are explained.

\subsection{Ice sample preparation and composite coupons}

The ice projectiles were obtained following a two step manufacturing process. In the first step, an ice block in which the air bubbles are concentrated at the bottom is manufactured; in the second step the ice is melted into the desired shape by means of two pre-warmed aluminium blocks and a combination of gravity load and heat conduction. This melting process avoids to use any carving process which can produce cracks inside the ice projectile. It is worth to mention that the micro structure of the ice block obtained is columnar granular which is different from the hailstones formed in nature; nevertheless the results showed by Kim et al. [31] concluded that the effect of micro structure of ice can be neglected under impact conditions (at high strain rates). A more detailed description about the ice projectile manufacturing process can be found in a previous work of the same authors of the current [30]. The selection of the ice diameter was done based on the natural distribution of hail sizes measured in different airports under severe storms. The diameter of the hail follows a normal distribution, in which the 90th percentile corresponds to $44.7 \mathrm{~mm}$ and the 95th to $50.8 \mathrm{~mm}[31,32]$. In addition, the European Aviation Safety Agency [39] considers severe in-flight hail (category 2 damage), when it has an approximate diameter of $50 \mathrm{~mm}$. It was considered for this work that a size of $50 \mathrm{~mm}$ in diameter (57 g of mass) could represent a large hail, whereas $40 \mathrm{~mm}$ ( $29 \mathrm{~g}$ of mass) is representative to a medium size hail.

Since the ice properties exhibit a sensible dependence with the temperature [23], in order to assure a constant temperature of the projectile during the test, the ice spheres were kept at $-12^{\circ} \mathrm{C}$ almost 2 hours before impact. Impact tests were conducted under room conditions due to the fact that the impact results are independent from the room temperature as it is shown in the works of Render and Pan [40,41]; also the composite laminates were kept at room conditions.

The composite materials chosen for these experimental tests were unidirectional carbon/epoxy laminates manufactured using autoclave methods. These materials and process were chosen because they are commonly used in the aeronautic industry; the manufacturing process was carried out by the Spanish National Institute of Aeronautical Techniques. All panels used in these studies were square plates of $300 \mathrm{~mm}$ side, with two different thicknesses 4 and $6 \mathrm{~mm}$. The laminates were composed respectively by 21 and 32 plies of AS4 fibres with 8552 epoxy matrix, manufactured by Hexcel. Table 1 
Table 1

Ply sequence of laminates used.

\begin{tabular}{|c|c|c|}
\hline Laminate & Ply sequence & Thickness \\
\hline 21 Plies & $(45 /-45 / 90 / 0 / 90 /-45 / 45 / 90 / 0 / 90 / 0) S^{\prime}$ & $4 \mathrm{~mm}$ \\
\hline 32 Plies & $(45 /-45 / 90 / 0 / 90 /-45 / 45 / 90 / 0 / 90 / 45 /-45 / 90 / 90 /-45 / 45) S$ & $6 \mathrm{~mm}$ \\
\hline
\end{tabular}

shows the ply sequence of the different laminates employed in the test; both sequences were chosen due to their widespread use in the industry.

\subsection{Test procedure}

In order to perform the high velocity ice impact tests, a one stage pneumatic launcher with a $5 \mathrm{~m}$ long barrel and a $60 \mathrm{~mm}$ of calibre (Fig. 1) was used. The launcher uses compressed air to impel the projectile; the pressure used in the test can be varied, in order to reach different impact velocities. Two laser barriers are located at the exit of the barrel muzzle in order to measure the projectile velocity before impacting the composite target. Laminates were clamped using a steel frame located in front of the cannon, leaving a free span of $280 \times 280 \mathrm{~mm}$. Since no panel perforation was expected, a laser extensometer (MEL-M27L/20) was placed at the back of the composite coupon. It allows to measure the out-of-plane

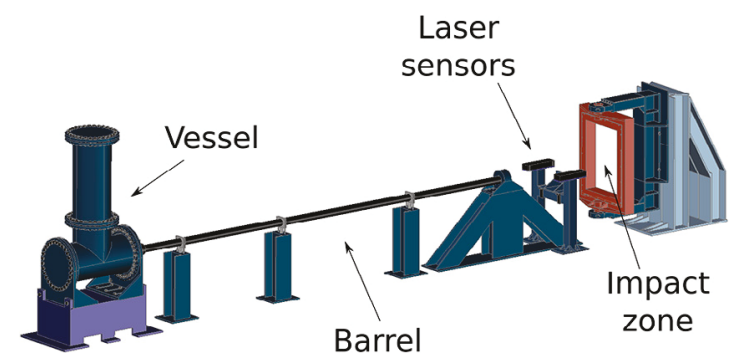

Fig. 1. One stage pneumatic launcher.

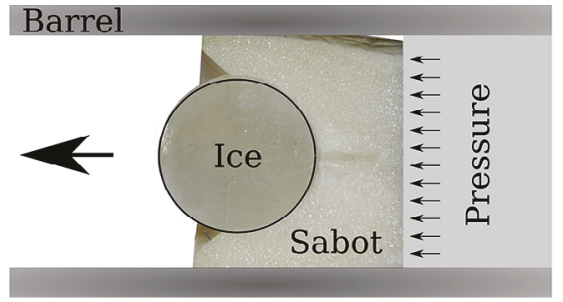

Fig. 3. Section of $40 \mathrm{~mm}$ diameter ice with sabot inside the barrel.

displacement of the laminate centre during the impact process; the maximum range of the laser is $20 \mathrm{~mm}$, which is high enough to measure the laminate maximum deflection. The impact event has been recorded by means of a high speed camera (Photron Ultima APX); the lighting was provided by an HMI lamp. A setup scheme of the experiments can be observed in Fig. 2.

A sabot was developed to launch the ice due to the difference between the calibre of the barrel and the ice diameter. The sabot was made of polyurethane foam, which isolates thermally the ice (Fig. 3). In addition it also protects the ice during the acceleration in order to avoid the appearance of cracks. The aerodynamic design of the sabot allows to deflect its trajectory in order to avoid its impact on the target. Using this setup, the ice spheres impact perpendicularly to the plane of the composite laminate in a velocity range between 50 and $250 \mathrm{~m} / \mathrm{s}$.

After the test, composite laminates were analysed using both destructive and non-destructive techniques. The C-scan was used to measure the total delaminated area with precision. The phasearray system was used to evaluate the position of the delamination along the thickness, which will help on the understanding of the failure process. Finally, some of the laminates were cut using a diamond saw (Well model 3242) avoiding any modification of the existent damage; this cut will allow to observe damages through thickness of the laminate.

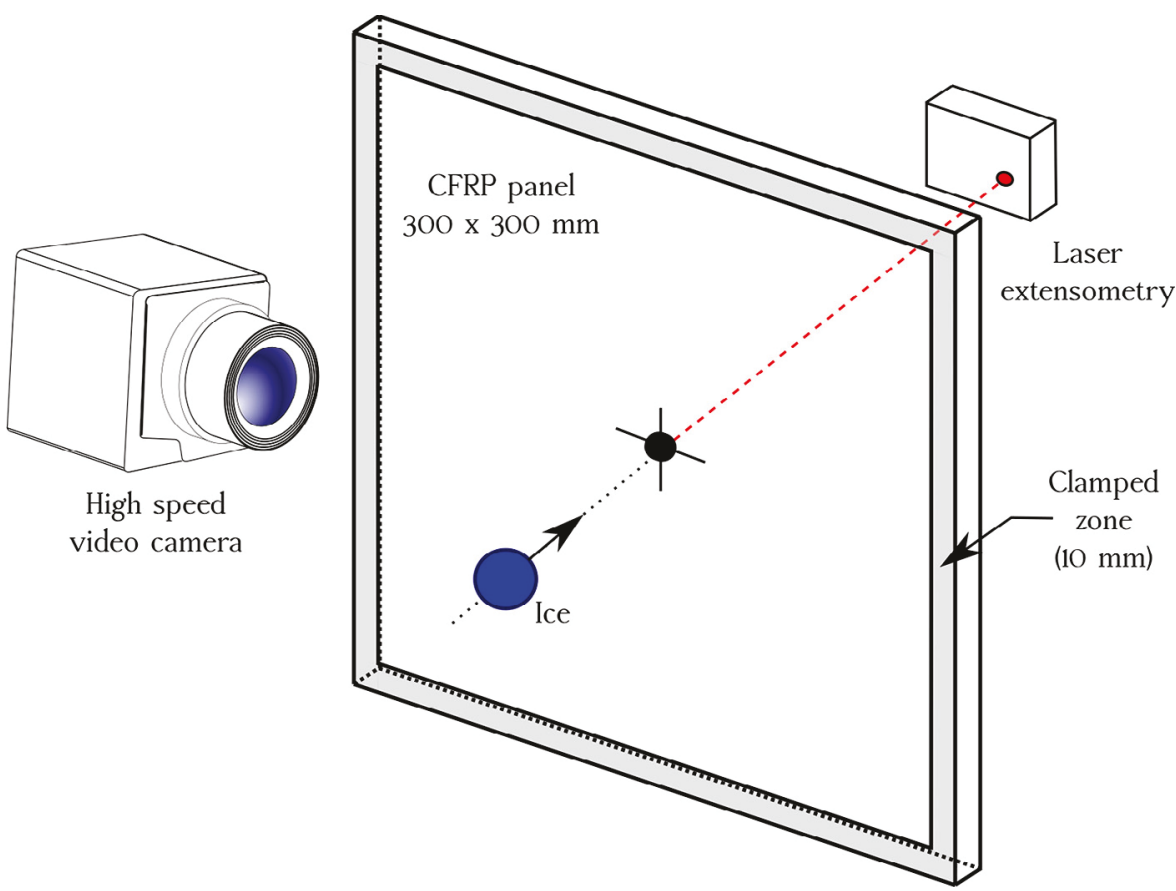

Fig. 2. Experimental scheme. 


\section{Analysis of impacts on composite panels}

The damage induced in the composite plates by the ice impact has been analysed from different points of view: visual external inspection, deflection of the plates during the impact and internal inspection (using both non-destructive and destructive techniques). In this section, the results of this study are presented.

\subsection{Visual inspection}

The impacted laminates only show barely visual external damages. The composite plates impacted at low velocity (or low kinetic energy) do not show any sign of damage in any of its faces; neither in its front face (where the projectile impacts), nor in its back face. As the kinetic impact energy increases, external damage appears firstly in the back face of the specimen in the form of fibre debonding (Fig. 4). Higher impact kinetic energy promotes external damages at the impacted face laminates, as can be shown in Fig. 5, where a $4 \mathrm{~mm}$ thickness laminate (impacted at $\sim 1200 \mathrm{~J}$ ) shows some fibre tows debonded; the back face of the laminate shows similar damages as previously described.

For the different laminate thicknesses and ice diameters studied in this work, no differences were found in the type of external damages or in the order of apparition (as the kinetic impact energy increases). Nevertheless the impact energy at which damage appears in the front and back faces is different for each combination of parameters (laminate thickness and ice diameter). Table 2 summarizes the values of the critical kinetic impact energies and impact velocities at which the back face shows damage. In all of the cases studied, the ice projectile did not perforate nor produced a visual crack all through the thickness of the plates. This kind of failure is different from the one observed by other authors in woven laminates [31]. Other authors [38] which studied hybrid tape laminates do not report this kind of damage probably because of the hybridization (laminates were made from carbon/epoxy and glass/epoxy plies) or because the energies considered were lower.

Table 2

Critical energies for the visual damages observed at the back face.

\begin{tabular}{lll}
\hline Plate thickness & $\phi$ Projectile & Critical velocity (energy) for visual damage \\
\hline $4 \mathrm{~mm}$ & $40 \mathrm{~mm}$ & $199 \mathrm{~m} / \mathrm{s}(\sim 575 \mathrm{~J})$ \\
& $50 \mathrm{~mm}$ & $160 \mathrm{~m} / \mathrm{s}(\sim 725 \mathrm{~J})$ \\
$6 \mathrm{~mm}$ & $40 \mathrm{~mm}$ & $242 \mathrm{~m} / \mathrm{s}(\sim 850 \mathrm{~J})$ \\
& $50 \mathrm{~mm}$ & $223 \mathrm{~m} / \mathrm{s}(\sim 1400 \mathrm{~J})$ \\
\hline
\end{tabular}

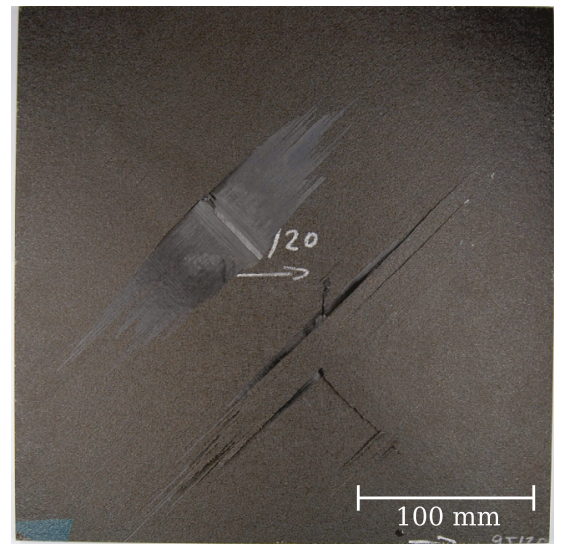

Fig. 5. Damage at front face in a 21 plies laminate impacted by a sphere of $50 \mathrm{~mm}$ at $200 \mathrm{~m} / \mathrm{s}(1140 \mathrm{~J})$.

\subsection{Composite plate deflection}

The displacement of the centre of the plate, measured by the laser during the impact, is shown for different projectile diameters and velocities in Fig. 6 . When the plates are impacted, the deflection grows until reaching a plateau and then decreases to zero at around 1-1.2 ms. As expected, the higher the impact velocity, the higher the deflection. It is important to note that impacts at higher velocities present a sudden increase in displacement at the end of the plateau. This kind of response is usually associated to a change in the stiffness of the composite plate. Since boundary conditions do not change during the impact test, it is reasonable to relate the reduction of the stiffness to the appearance of damage in the plate in the form of delamination. Finally, regarding the influence of the projectile diameter on the deflection, it is worth to mention that the same behaviour is observed; the only difference is that a larger diameter (and hence mass) promotes larger displacement values. Same trend with different values is observed for the $6 \mathrm{~mm}$ thickness laminates.

Fig. 7 summarizes the maximum values of out-of-plane displacement measured by the laser during the impacts. The displacement increases with the impact velocity; the combination of the bigger ice projectile and the thinner laminates induces the maximum displacements as expected. The relation between the displacement and the impact velocity seems to be linear with low spread; the sudden increase related to the internal damage

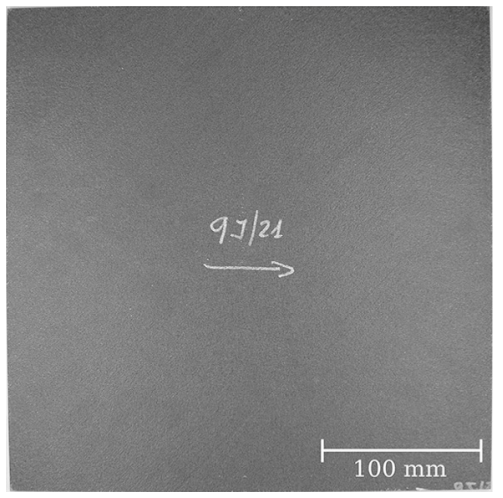

(a) No visual damage at front face

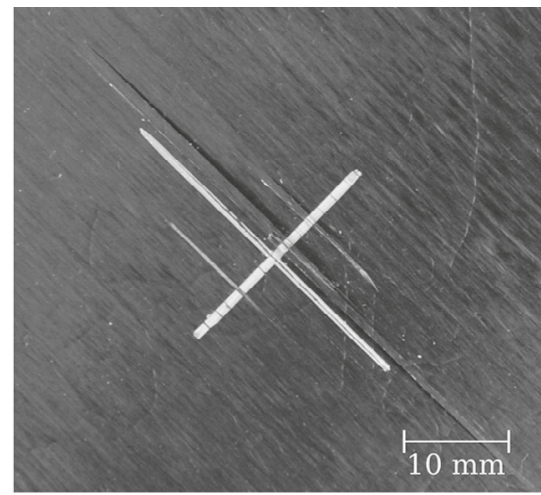

(b) Zoom of damage at back face

Fig. 4. Visual damages in a $4 \mathrm{~mm}$ plate impacted by a sphere of $50 \mathrm{~mm}$ at $154 \mathrm{~m} / \mathrm{s}(675 \mathrm{~J})$. 


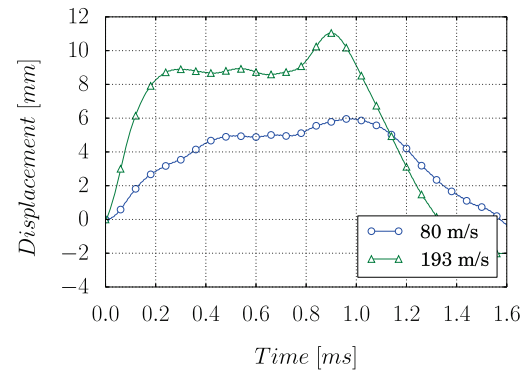

(a) $\phi=40 \mathrm{~mm}$

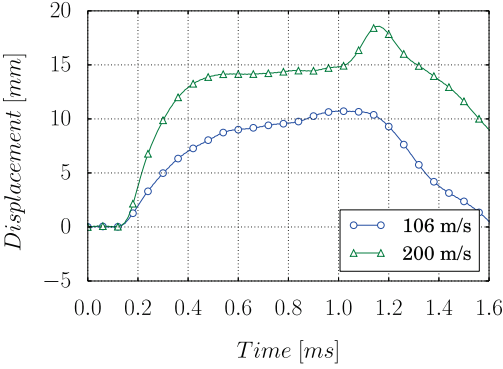

(b) $\phi=50 \mathrm{~mm}$

Fig. 6. Displacement out of laminate plane of the central point during the impact for 21 plies laminate.

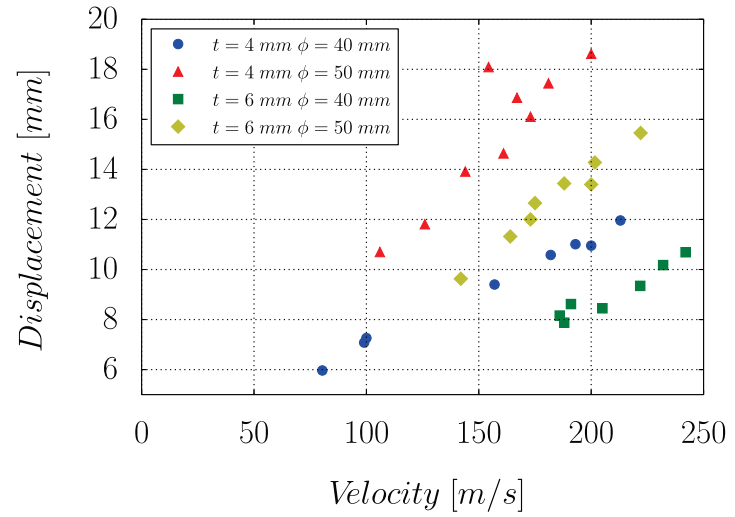

Fig. 7. Maximum displacement measured by the laser for the two plate thickness and different projectile diameter. (previously described) is relatively small, and hence no appreciable change in the slopes of Fig. 7 can be observed.

\subsection{Impact process}

The impact tests were recorded using a high speed video camera in order to analyse the impact process and correlate it with the displacement response of the plate obtained by means of the laser extensometer. Fig. 8 shows different frames of an impact, synchronized with the measurements obtained by the laser extensometer (the example corresponds to a $50 \mathrm{~mm}$ ice projectile diameter impacting at $200 \mathrm{~m} / \mathrm{s}$ (the impact energy of this test is $\sim 1140 \mathrm{~J}$ ) against a $4 \mathrm{~mm}$ composite plate). The corresponding instant in the deflection curve is indicated by a vertical line. It is observed that, as soon as the ice projectile impacts the plate, it becomes completely
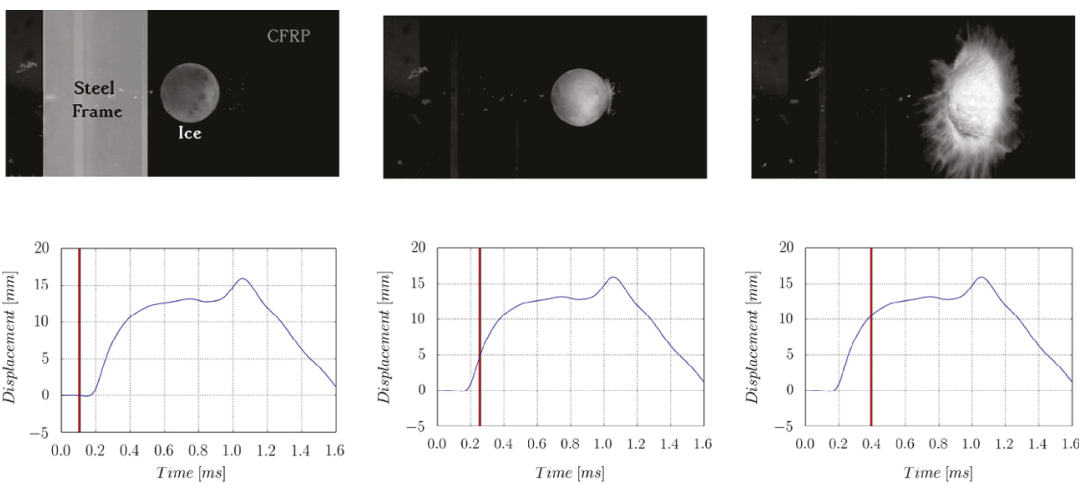

(a) $t=0.1 \mu \mathrm{s}$

(b) $t=0.25 \mu \mathrm{s}$

(c) $t=0.39 \mu \mathrm{s}$
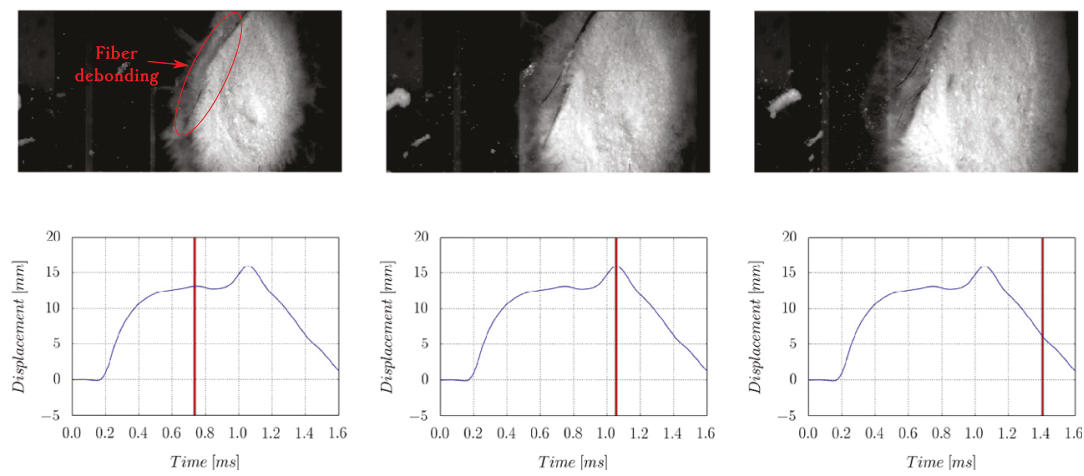

(d) $t=0.73 \mu \mathrm{s}$

(e) $t=1.05 \mu \mathrm{s}$

(f) $t=1.4 \mu \mathrm{s}$

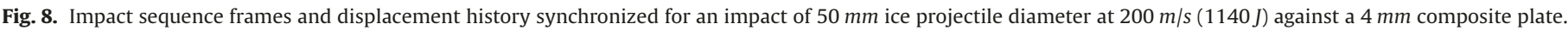




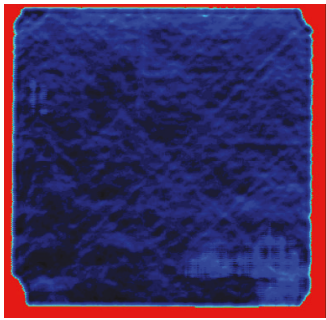

(a) No delaminated

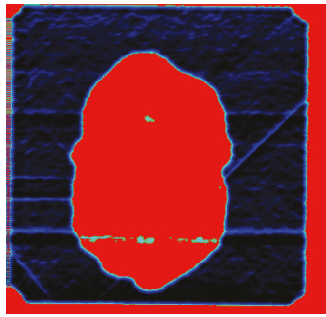

(b) Partly delaminated

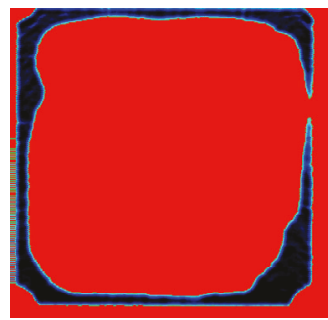

(c) Fully delaminated $(>75 \%)$

Fig. 9. Ultrasonic scan of laminates impacted at different velocities.

fragmented losing its transparency due to the appearance of new surfaces in the cracks that reflect the light [30]; at that instant the displacement starts to increase (Fig. 8(b)). Since the thickness reduction of the plate is negligible, the displacement of the front face and back face could be considered the same. At $t=0.75 \mu \mathrm{s}$ in Fig. 8(d) some fibre debonding can be distinguished at the upper left quarter of the composite plate (as indicated in the previous section). This kind of damage does not reduce significantly the stiffness of the plate, and the displacement measurement is not affected appreciably. In fact, a few microseconds later (Fig. 8(e)), the displacement history shows the sudden increase already commented; since no difference in the external damage is appreciated, the change of stiffness could be associated to an internal damage of the laminate. Finally, the last image of the impact process shows that once the maximum peak displacement is reached, the ice projectile is completely deflected in a direction parallel to the laminate surface, and the force performed tends to zero.

\subsection{Destructive and non-destructive inspections}

In order to study the internal damage of the plates, ultrasonic techniques were used before (to assure the panel integrity) and after the impact. Fig. 9 shows the C-scan inspection of different CFRP laminates; Fig. 9(a) depicts a $6 \mathrm{~mm}$ plate impacted by $40 \mathrm{~mm}$ ice projectile at $150 \mathrm{~m} / \mathrm{s}$ in which no delamination (depicted in blue) is observed; Fig. 9(b) and (c) show plates which contain different amount of delamination (depicted in red). The C-scan results of most of the impacted plates show extreme situations; no delamination or a great amount of delamination appears, only a few plates show partly delamination as can be observed in Fig. 9(b). The composite panels that exhibit delamination correspond to the ones that show a sudden increase in the deflection (previously explained).

The summary of delaminated area versus the impact velocity for both thicknesses and ice projectile diameters is shown in Fig. 10. These graphs show that the transition between zero delamination

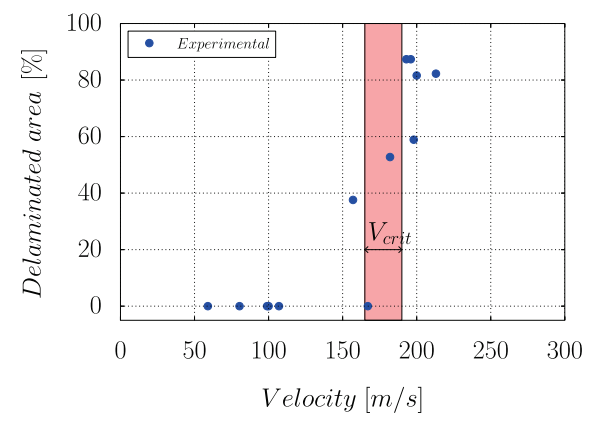

(a) $t=4 \mathrm{~mm} \phi=40 \mathrm{~mm}$

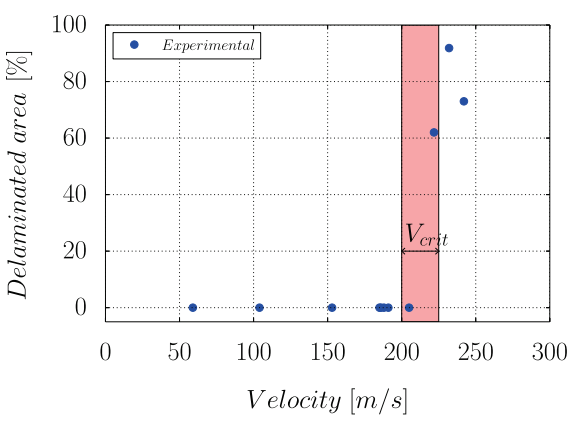

(c) $t=6 \mathrm{~mm} \phi=40 \mathrm{~mm}$

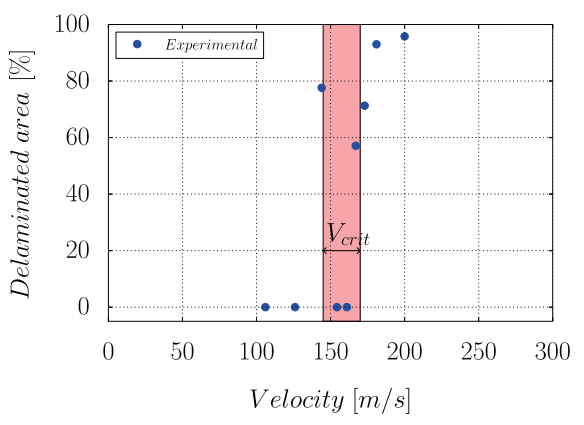

(b) $t=4 \mathrm{~mm} \phi=50 \mathrm{~mm}$

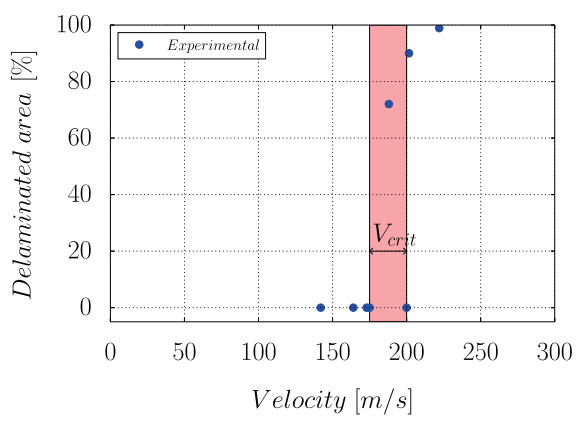

(d) $t=6 \mathrm{~mm} \phi=50 \mathrm{~mm}$

Fig. 10. Delaminated area against impact velocity for the two plate thickness and different projectile diameter. 


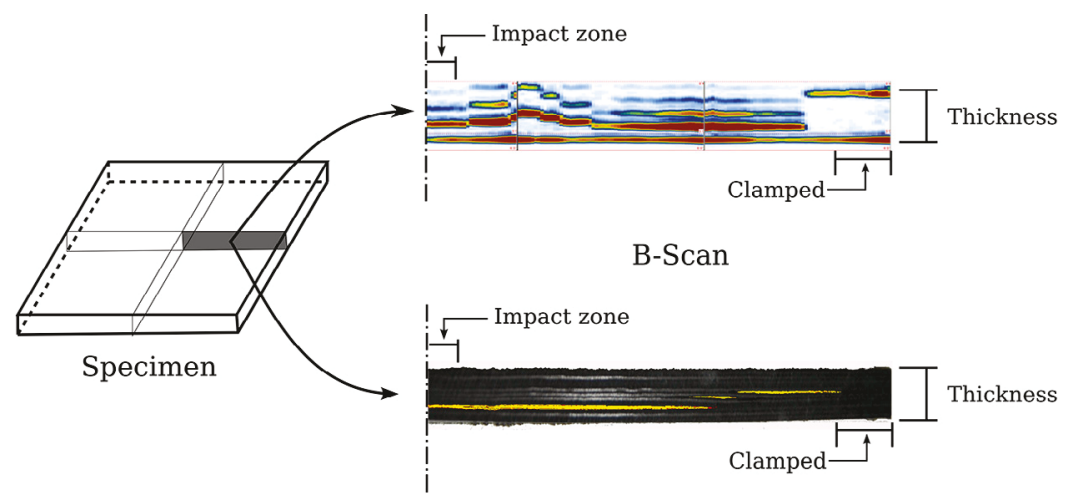

Through thickness cut

Fig. 11. B-Scan and through thickness cut of a $4 \mathrm{~mm}$ thickness composite plate impacted by a $40 \mathrm{~mm}$ diameter ice projectile at $193 / \mathrm{s}$ ( $540 \mathrm{~J}$ ).

to full delamination (delaminated area greater than 75\%) occurs in a narrow range of velocities. In fact it is possible to define a critical velocity (for each ice diameter and composite thickness combination) that establishes this sudden transition.

In order to study the location of internal damages and confirm that the main damage produced corresponds to delamination, B-scan analysis as well as through thickness cuts have been performed. Fig. 11 shows both inspections for a section at the middle of the laminate specimen; in the B-scan the delamination is depicted in red and in the through thickness it is highlighted in yellow. Both images show that the delamination appears mainly between two plies that are close to the back face; in addition it is possible to observe that the delamination zone ends close to the clamping area. Since the identified delamination is located approximately at one-third of the laminate thickness (close to the rear face), a reduction of the laminate stiffness is expected, which could explain the sudden increase in the deflection time history curves.

Once the panels are analysed using different techniques, it is possible to state that the minimum impact energy needed to promote delamination is lower than the one needed to promote external debonding. For instance a $4 \mathrm{~mm}$ thickness composite panel impacted with a $40 \mathrm{~mm}$ diameter ice, exhibits delamination for impact velocities of approximately $170 \mathrm{~m} / \mathrm{s}$, which corresponds to $420 \mathrm{~J}$; the back face debonding appears for an impact velocity of $199 \mathrm{~m} / \mathrm{s}$, which corresponds to an energy of $575 \mathrm{~J}$.

\section{Discussion of experimental results}

In this section a discussion about the influence of the parameters considered on the damage induced in the composite plate is performed. Additionally, a definition of a dimensionless variable has been proposed to include the effect of all the studied parameters. This proposed variable could be used by researchers and engineers in preliminary estimations for designing laminates that could be subjected to ice impact. This variable will be used to calculate the critical velocity that produces damage in the composite plate.

\subsection{Analysis of impact parameters}

Delamination is the main damage mechanism that composite laminates exhibits. In order to analyse under which circumstances it appears, Table 3 summarizes the critical velocities $\left(V_{c}\right)$ and the critical kinetic energies $\left(K E_{c}\right)$ needed to promote this type of failure. The critical velocity is obtained using Fig. 10, by performing an average of the marked zone (which corresponds to the abrupt transition from no delamination to full delamination). For all the combinations of ice diameter and composite thickness, the impact velocity (or kinetic energy) needed to induce internal damage is lower than the one needed to induce external damage (Table 2). This is an important conclusion since it means that internal damage could exist without any external visible evidence.

The analysis of the influence of ice projectile diameter and laminate thickness could be performed using Table 3. Concerning the projectile diameter, it is necessary lower impact velocity to produce delamination as the ice diameter increases (and therefore the mass), which is also an expected result. However, kinetic energy has an opposite trend, in fact as the diameter increases, the kinetic energy needs also to be increased. This last result could be explained taking into account that larger projectiles have larger frontal area $\left(A_{f}\right)$; the smaller the area, the more localized is the impact, promoting easily the apparition of delamination. In fact the critical impact kinetic energy per unit of area $\left(K E_{c} / A_{f}\right)$ is approximately constant for each laminate thickness (Table 3 ).

As expected, the higher the laminate thickness, the higher the impact velocity (or kinetic energy) necessary to promote internal damage. In order to evaluate the dependence of that parameter, Table 3 shows in its last column the value of $K E_{c} /\left(A_{f} t\right)$ where $t$ is the laminate thickness. The values obtained are almost constant for the four cases analysed, and hence it is possible to state that the ice projectile kinetic energy needed to promote delamination in the composite panel is proportional to the frontal projectile area and to the laminate thickness:

$K E_{c} /\left(A_{f} t\right)=C_{1} \Rightarrow K E_{c}=C_{1} \cdot\left(A_{f} t\right)$

where $C_{1} \sim 85 \cdot 10^{6}$ is the constant obtained.

In order to analyse if this constant defines the transition between no delamination to full delamination with accuracy, Fig. 12 shows this transition; in this plot the $x$ axis is the variable $K E /\left(A_{f} t\right)=\xi$ (where $K E$ is the kinetic energy of the impact) and the $y$ axis is the delaminated area which varies from $0 \%$ to $100 \%$. The graph confirms that the variable $\xi$ describes with enough accuracy if a determined test promotes delamination or not. The constant $C_{1}$

Table 3

Threshold velocities for different plate thickness and ice projectile diameter.

\begin{tabular}{lllll}
\hline $\begin{array}{l}\text { Plate } \\
\text { thickness }\end{array}$ & $\begin{array}{l}\text { Projectile } \\
\phi\end{array}$ & $V_{c}\left(K E_{c}\right)$ & $K E_{c} / A_{f}$ & $K E_{c} /\left(A_{f} t\right)$ \\
\hline $4 \mathrm{~mm}$ & $40 \mathrm{~mm}$ & $\sim 172 \mathrm{~m} / \mathrm{s}(429 \mathrm{~J})$ & $\sim 341 \cdot 10^{3} \mathrm{~J} / \mathrm{m}^{2}$ & $\sim 85 \cdot 10^{6} \mathrm{~J} / \mathrm{m}^{3}$ \\
& $50 \mathrm{~mm}$ & $\sim 153 \mathrm{~m} / \mathrm{s}(667 \mathrm{~J})$ & $\sim 340 \cdot 10^{3} \mathrm{~J} / \mathrm{m}^{2}$ & $\sim 85 \cdot 10^{6} \mathrm{~J} / \mathrm{m}^{3}$ \\
$6 \mathrm{~mm}$ & $40 \mathrm{~mm}$ & $\sim 212 \mathrm{~m} / \mathrm{s}(652 \mathrm{~J})$ & $\sim 519 \cdot 10^{3} \mathrm{~J} / \mathrm{m}^{2}$ & $\sim 86 \cdot 10^{6} \mathrm{~J} / \mathrm{m}^{3}$ \\
& $50 \mathrm{~mm}$ & $\sim 188 \mathrm{~m} / \mathrm{s}(1010 \mathrm{~J})$ & $\sim 513 \cdot 10^{3} \mathrm{~J} / \mathrm{m}^{2}$ & $\sim 85 \cdot 10^{6} \mathrm{~J} / \mathrm{m}^{3}$ \\
\hline
\end{tabular}




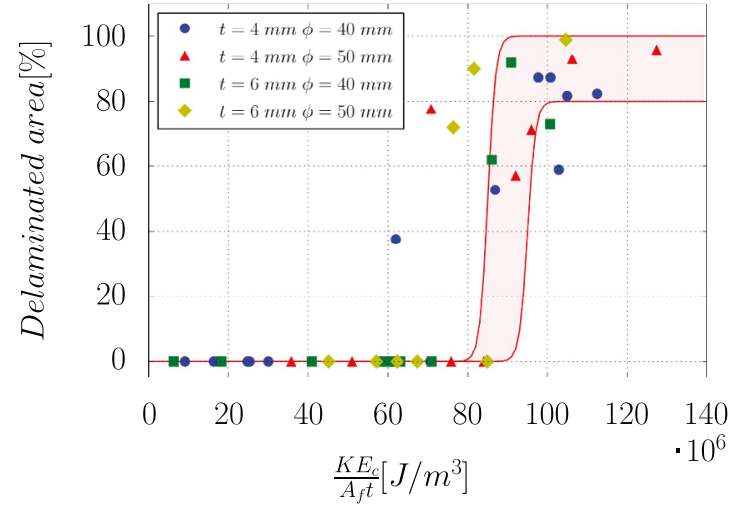

Fig. 12. Delaminated area versus the non-dimensional variable $\xi$.

appears to be the value that indicates the transition between no damage and full damage.

\subsection{Validation with other results}

The variable $\xi$ obtained in the previous section should be compared with experimental results performed by other authors in order to verify its validity. To perform this comparison, a dimensionless form of this expression should be used. This new variable $\xi^{*}$ is obtained converting to dimensionless each of the three parameters: $K E_{c}, t$ and $A_{f}$. A dimensionless version of the critical kinetic energy is obtained dividing it by the energy absorbed by one interply through delamination, which is $G_{I I C} L^{2}$, where $G_{I I c}$ is the interlaminar fracture toughness in mode II (the delamination growth is supposed to be dominated by this opening mode) and $L$ is the length side of the free area of the composite panel. The dimensionless ice frontal area is obtained dividing it by $L^{2}$. Finally the dimensionless laminate thickness is achieved dividing it by $L$ also. The expression for the dimensionless variable $\xi^{*}$ is:

$\xi^{*}=\frac{K E_{c} L^{2} L}{A_{f} t G_{I I C} L^{2}}$

Rearranging the terms and using the extended expressions for $K E_{C}$ and $A_{f}$ the equation leads to

$\xi^{*}=\frac{V_{c}^{2} L \phi \rho}{3 t G_{I I c}}$

where $\rho$ is the ice density. The corresponding value for $\xi^{*}$ at which the transition occurs between no delamination and full delamination is $\xi^{*} \sim 3 \cdot 10^{4}$ (using $G_{I I c}=750 \mathrm{~J} / \mathrm{m}^{2}[42]$ ). Eq. (3) could be used to define a threshold between no delamination to full delamination for any variable. In particular it will be interesting to check if it defines adequately the critical velocity, which in fact is the impact velocity threshold. Fig. 13 shows the experimental tests accomplished in the current work, plotting the impact velocity in the $y$ axis and the projectile diameter in the $x$ axis; the tests in which delamination appears are represented with an " $x$ " and the ones that do not are represented by a circle. The blue line is the Eq. (3) in the form:

$V_{c}=\sqrt{\frac{3 \xi^{*} t G_{I I c}}{L \rho \phi}}$

It is clear that this function divides the tests in the two aforementioned groups (Fig. 13) for both the projectile diameters analysed.

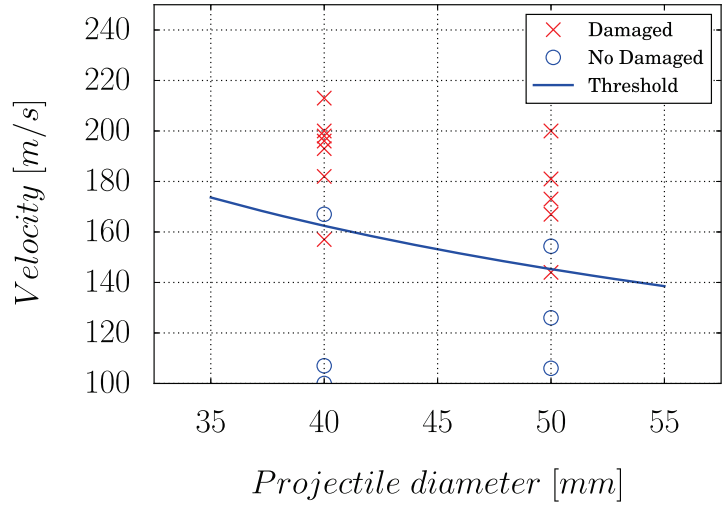

(a) $4 \mathrm{~mm}$ thickness laminate

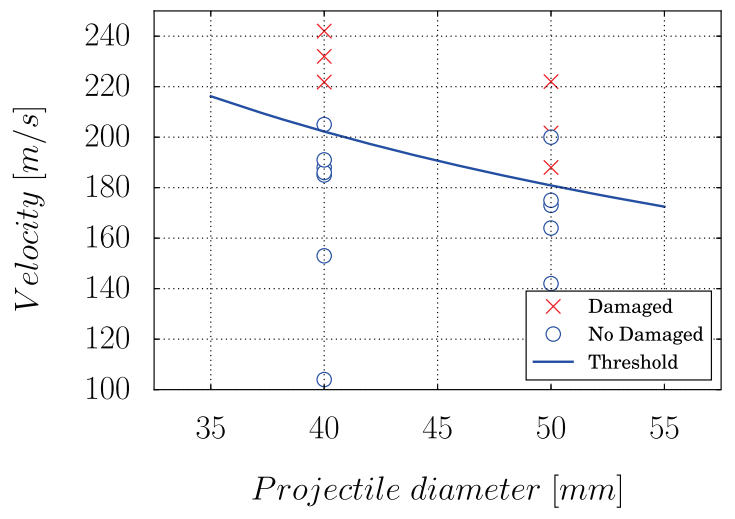

(b) $6 \mathrm{~mm}$ thickness laminate

Fig. 13. Experimental and proposed damage threshold for both laminate thicknesses and ice diameters.

The tests in which there is delamination remain above the line, whereas the non-delaminated tests stay below it. As shown in Fig. 10 the critical velocity is a range rather than an exact value; this is the reason why, due to the experimental dispersion, there are two specimens slightly misplaced. As expected this threshold line decreases as the projectile diameter increases. Comparing the two figures (for 4 and $6 \mathrm{~mm}$ laminate thickness respectively), the critical impact velocity increases with the laminate thickness.

The proposed equation has proven to be valid in the range of parameters studied in the present work. In order to study if it is valid in a wider range, the experimental results from Kim et al. [31] are going to be used. In this work the composite panel size is $305 \times 305 \mathrm{~mm}^{2}$ (free span of $260 \times 260 \mathrm{~mm}^{2}$ ) and the ice diameters studied are $\phi=25.4,40.7,50.8 \mathrm{~mm}$. The material of the panels was the same as that used in this work, but with another architecture (woven 8 harness satin); the thickness was also different 1.22 and $2.44 \mathrm{~mm}$. Fig. 14 represents the threshold velocity as function of the ice projectile diameter; in this graph the triangular markers correspond with the threshold velocities obtained by Kim et al. [31], and the lines with the equation proposed in the current work (Eq. (4)). Appropriate values were used for the variables $L$ (obtained from the article of Kim et al. [31]) and $G_{\text {IIC }}$ (obtained from Ref. [42,43]). It is clear that the trend is the same, and that some differences exist although they are within reasonable limits taken into account the simplicity of the equation, and that some differences exist between the experimental setups of the two works. 


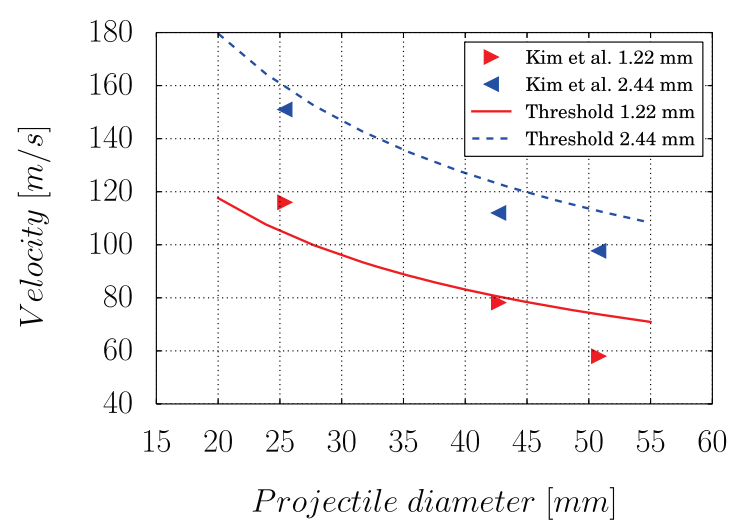

Fig. 14. Comparative thresholds for the experimental results obtained by Kim et al. [31] and the proposed in this article.

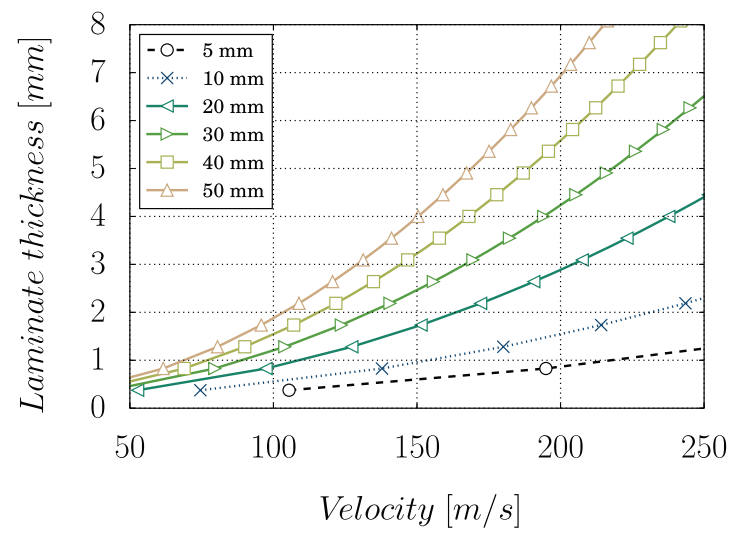

Fig. 15. Proposed safe design curves for unididrectional AS4/8552 $\left(300 \times 300 \mathrm{~mm}^{2}\right)$ against ice sphere impacts.

\subsection{Implications for design of composite structures}

The data and the analysis presented in this study for different laminate plates and different ice projectile diameters allow proposing a guidance in safe design for composite plates against ice sphere impact. To this end, using the aforementioned equation it is possible to define threshold design curves, which are represented in Fig. 15. In this graph, the critical laminate thickness is represented in the $y$ axis, and the impact velocity in the $x$ axis; different curves exist for the different ice diameters. For a given ice diameter and impact velocity, the graphs define the critical laminate thickness where a sudden transition between no delamination to full delamination occurs. For instance the critical laminate thickness for a $40 \mathrm{~mm}$ ice diameter projectile impacting at $150 \mathrm{~m} / \mathrm{s}$ will be $3 \mathrm{~mm}$. Hence a thickness of $4 \mathrm{~mm}$ ( $3 \mathrm{~mm}$ promotes damage) could be a good start point to perform more accurate simulations or perform experimental tests.

\section{Conclusion}

In this work the analysis of the thread of ice projectiles in composite laminates has been accomplished. High velocity impact tests have been performed in a wide range of impact velocities, for two different hail diameters and two different composite thicknesses. An experimental procedure has been developed in order to launch ice spheres at high velocities perpendicular to composite laminates. To this end a special experimental setup was developed measuring the out-of-plane displacement of the central point of the laminate and synchronizing the signal with the video recorded. Moreover a complete non-destructive study of the damage has been accomplished using different ultrasonic techniques. The data collected from the experimental results allow studying the influence of the different parameters studied in the internal damages of the laminates. The main conclusions are as follows:

- The ice sphere projectiles do not penetrate the composite laminates in the range of study; the ice get fragmented during the first instants of the impact and the small particles deflect and spread along the composite plate reducing the penetration capability of the projectile.

- The main damage observed in the laminates was inter-lamina failure. The delamination appears before any visual damage could be observed in the specimen. In most of the cases the failure extension is massive when a certain impact velocity is reached. This transition velocity has been measured through an extensive experimental campaign for both ice diameter and thickness.

- The out-of-plane displacement measured during the impact suffers a sudden increase followed by a plateau which ends with a smooth decreasing for the cases in which the laminate does not show delamination. In the delaminated ones, the plateau present a small peak that can be related to the damage apparition.

- The ultrasonic techniques allow to locate the delamination through the thickness of the plate. The inter lamina failure appears near to the back or not impacted face of the composite plate. Moreover the destructive techniques assure that the main damage is the delamination.

- The experimental results allow to define the influence of the different parameters considered (laminae thickness and ice projectile diameter), through the definition of a dimensionless variable. This variable could be used as pre-design tool to perform preliminary analysis.

\section{Acknowledgements}

This research was done with the financial support of the Spanish Ministry of Economy and Competitiveness under Project reference DPI2013-41094-R. 


\section{References}

[1] Cantwell WJ, Morton J. Detection of impact damage in CFRP laminates. 1985;3:241-57.

[2] Jang BZ, Chen LC, Wang CZ, Lin HT, Zee RH. Impact resistance and energy absorption mechanisms in hybrid composites. Compos Sci Technol 1989;4:305-35.

[3] Cantwell WJ, Morton J. The influence of varying projectile mass on the impact response of CFRP. Compos Struct 1989;13:101-14.

[4] Cantwell WJ, Morton J. Comparison of the low and high velocity impact response of cfrp. Composites 1989;20:545-51.

[5] Srinivasan K, Coats TW, Kingley JA. Shear failure and impact resistance in graphite fiber laminates. J Compos Tech Res 1992;14:231-4.

[6] L'opez-Puente J, Zaera R, Navarro C. The effect of low temperatures on the intermediate and high velocity impact response of CFRPs. Composites Part B 2002;33:559-66.

[7] López-Puente J, Zaera R, Navarro C. High energy impact on woven laminates. J Phys IV 2003;110:639-44.

[8] Ulven C, Vaidya UK, Hosur MV. Effect of projectile shape during ballistic perforation of VARTM carbon/epoxy composite panels. Compos Struct 2003;61:143-50.

[9] Whittingham B, Marshall IH, Mitrevski T, Jones R. The response of composite structures with pre-stress subject to low velocity impact damage. Compos Struct 2004;66:685-98.

[10] Mitrevski T, Marshall IH, Thomson R, Jones R, Whittingham B. The effect of impactor shape on the impact response of composite laminates. Compos Struct 2005;67:139-48.

[11] Hosseinzadeh R, Shokrieh MM, Lessard L. Damage behavior of fiber reinforced composite plates subjected to drop weight impacts. Compos Sci Technol 2006;66:61-88.

[12] Lopresto V, Melito V, Leone C, Caprino G. Effect of stitches on the impact behaviour of graphite/epoxy composites. Compos Sci Technol 2006;66:20614. 
[13] L'opez-Puente J, Zaera R, Navarro C. An analytical model for high velocity impacts on thin CFRPs woven laminated plates. Int J Solids Struct 2007;44:2837-51.

[14] Millett JCF, Bourne NK, Meziere YJE, Vignjevic R, Lukyanov A. The effect of orientation on the shock response of a carbon fibre-epoxy composite. Compos Sci Technol 2007;67:3253-60.

[15] Fernandez-Fdz D, L'opez-Puente J, Zaera R. Prediction of the behaviour of CFRPs against high-velocity impact of solids employing an artificial neural network methodology. Composites Part A 2008;39:989-96.

[16] L'opez-Puente J, Zaera R, Navarro C. Experimental and numerical analysis of normal and oblique ballistic impacts on thin carbon/epoxy woven laminates. Composites Part A 2008;39:374-87.

[17] L'opez-Puente J, Varas D, Loya J, Zaera R. Analytical modelling of high velocity impacts of cylindrical projectiles on carbon/epoxy laminates. Composites Part A 2009;40:1223-30.

[18] Johnson AF, Pickett AK, Rozycki P. Computational methods for predicting impact damage in composite structures. Compos Sci Technol 2001;61:218392.

[19] Tita V, Carvalho J, Vandepitte D. Failure analysis of low velocity impact on thin composite laminates: Experimental and numerical approaches. Compos Struct 2008;83:413-28.

[20] Johnson AF, Holzapfel M. Modelling soft body impact on composite structures. Compos Struct 2003;61:103-13.

[21] McCarthy MA, Xiao JR, McCarthy CT, Kamoulakos A, Ramos J, Gallard JP, Melito V. Modelling of bird strike on an aircraft wing leading edge made from fibre metal laminates - Part 2: Modelling of impact with SPH bird model. Appl Compos Mater 2004;11:317-40.

[22] Hou JP, Ruiz C. Soft body impact on laminated composite materials. Composites Part A 2007;38:505-15.

[23] Cole D. Crack nucleation in polycrystalline ice Cold Reg Sci Technol $1988 ; 15: 79-87$. 
[22] Hou JP, Ruiz C. Soft body impact on laminated composite materials. Composites Part A 2007;38:505-15.

[23] Cole D. Crack nucleation in polycrystalline ice Cold Reg Sci Technol 1988;15:79-87.

[24] Schulson E. The brittle compressive fracture of ice. Acta Mater 1990;38:1963-76.

[25] Schulson E. Brittle failure of ice. Eng Fract Mech 2001;68:1839-87.

[26] Petrovic JJ. Mechanical properties of ice and snow. J Mater Sci 2003;38:16.

[27] Carney KS, Benson DJ, DuBois P, Lee R. A phenomenological high strain rate model with failure for ice. Int J Solids Struct 2006;43:7820-39.

[28] Combescure A, Chuzel-Marmot Y, Fabis J. Experimental study of highvelocity impact and fracture of ice. Int J Solids Struct 2011;48:2779-90.

[29] Pernas-S 'anchez J, Pedroche DA, Varas D, L'opez-Puente J, Zaera R. Numerical modeling of ice behavior under high velocity impacts. Int J Solids Struct 2012;49:1919-27.

[30] Pernas-S 'anchez J, Artero-Guerrero JA, Varas D, L'opez-Puente J. Analysis of Ice Impact Process at High Velocity. Exp Mech 2012;55:1669-79.

[31] Kim H, Welch DA, Kedward KT.Experimental investigation of high velocity ice impacts on woven carbon/epoxy composite panels. Composites Part A $2003 ; 34: 25-41$.

[32] Tippmann JD, Kim H, Rhymer JD. Experimentally validated strain rate dependent material model for spherical ice impact simulation. Int J Impact Eng 2013;57:43-54.

[33] Appleby-Thomas GJ, Hazell PJ, Dahini G. On the response of two commercially-important CFRP structures to multiple ice impacts. Compos Struct 2011;93:2619-27.

[34] Kim H, Kedward KT. Modeling hail ice impacts and predicting impact damage initiation in composite ctructures. AIAA Journal 2000;38:1278-88.

[35] Asp LE, Juntikka R. High velocity impact on NCF reinforced composites. Compos Sci Technol 2009;69:1478-82. 
[36] Hong YK, Park C, Baek SW. High-Velocity Impact of Ice Particles on a Composite Material. J Compos Mater 2009;43:1819-34.

[37] Juntikka R, Olsson R. Experimental and modelling study of hail impact on composite plates. 17th ICCM 2009.

[38] Rhymer J, Kim H, Roach D. The damage resistance of quasi-isotropic carbon/epoxy composite tape laminates impacted by high velocity ice. Composites Part A 2012;43:1134-44.

[39] Toso N, Johnson A. LIBCOS-Load upon impact behaviour of composite Structure. Research Project EASA.2009/3. European Aviation Safety Agency (EASA). 2011

[40] Pan H, Render PM. Impact Characteristics of Hailstones Simulating Ingestion by Turbofan Aeroengines. J Propul Power 1996;12:457-62.

[41] Render PM, Pan H. Experimental studies into hail impact characteristics. J Propul Power 1995;11:1224-30.

[42] Lopes CS, Camanho PP, G“urdal Z, Maimı P, Gonz'alez EV. Low-velocity impact damage on dispersed stacking sequence laminates. Part II: Numerical simulations. Compos Sci Technol 2009;69:937-47.

[43] Artero-Guerrero JA, Pernas-S 'anchez J, L'opez-Puente J, Varas D. On the influence of filling level in $\{\mathrm{CFRP}\}$ aircraft fuel tank subjected to high velocity impacts. Compos Struct 2014;107:570-77. 
[38] Rhymer J, Kim H, Roach D. The damage resistance of quasi-isotropic carbon/epoxy composite tape laminates impacted by high velocity ice. Composites Part A 2012;43:1134-44.

[39] Toso N, Johnson A. LIBCOS-Load upon impact behaviour of composite Structure. Research Project EASA.2009/3. European Aviation Safety Agency (EASA). 2011

[40] Pan H, Render PM. Impact Characteristics of Hailstones Simulating Ingestion by Turbofan Aeroengines. J Propul Power 1996;12:457-62.

[41] Render PM, Pan H. Experimental studies into hail impact characteristics. J Propul Power 1995;11:1224-30.

[42] Lopes CS, Camanho PP, G“urdal Z, Maim '1 P, Gonz'alez EV. Low-velocity impact damage on dispersed stacking sequence laminates. Part II: Numerical simulations. Compos Sci Technol 2009;69:937-47.

[43] Artero-Guerrero JA, Pernas-S 'anchez J, L'opez-Puente J, Varas D. On the influence of filling level in $\{\mathrm{CFRP}\}$ aircraft fuel tank subjected to high velocity impacts. Compos Struct 2014;107:570-77. 